\title{
Matrix-Assisted Laser Desorption Ionization Mass Spectrometry
}

National Cancer Institute

\section{Source}

National Cancer Institute. Matrix-Assisted Laser Desorption Ionization Mass

Spectrometry. NCI Thesaurus. Code C48040.

A mass spectrometric technique that is used for the analysis of large biomolecules.

Analyte molecules are embedded in an excess matrix of small organic molecules that show a high resonant absorption at the laser wavelength used. The matrix absorbs the laser energy, thus inducing a soft disintegration of the sample- matrix mixture into free (gas phase) matrix and analyte molecules and molecular ions. In general, only molecular ions of the analyte molecules are produced and almost no fragmentation occurs. This makes the method well suited for molecular weight determinations and mixture analysis. $(\mathrm{CHI})$ 